\title{
HUBUNGAN MOTIVASI KESEMBUHAN DENGAN KEPATUHAN MINUM OBAT PENDERITA TUBERKULOSIS PARU DI PUSKESMAS JAMBE KABUPATEN TANGERANG
}

\author{
*Mochammad Hasan, **Putri Nurjana Priyono \\ Program Studi S1 Keperawatan \\ STIKes Widya Dharma Husada Tangerang \\ Email : moch.hasan@yahoo.co.id
}

\begin{abstract}
ABSTRAK
Tuberkulosis paru tetap menjadi pembunuh utama pada tahun 2016. Ada sekitar 8,6 juta orang jatuh sakit dengan TB Paru dan 1,3 juta meninggal akibat TB Paru. Lebih dari 95\% kematian akibat TB Paru di Negara berpenghasilan rendah dan menengah, (WHO, 2013). TB Paru merupakan penyakit yang disebabkan oleh mycobacterium tuberculosis. Tujuan penelitian ini untuk mengetahui hubungan motivasi kesembuhan dengan kepatuhan minum obat pada pasien TB Paru di wilayah kerja Puskesmas Jambe Kabupaten Tangerang. Penelitian ini menggunakan jenis penelitian deskriptif analitik dengan pendekatan rancangan cross sectional. Metode sampling yang digunakan adalah Nonprobability Sampling dengan teknik accidental sampling. Variabel penelitian independen adalah motivasi kesembuhan dan variable dependen adalah kepatuhan minum obat pada penderita Tuberkulosis Paru. Populasi pasien TB Paru dewasa yang berobat di Puskesmas Jambe Kabupaten Tangerang 119 orang dengan besar sampel menggunakan rumus Slovin diperoleh 92 responden. Pengumpulan data primer penelitian menggunakan kuesioner dalam bentuk angket, dan pengumpulan data sekunder dari berkas rekam medis pasien. Analisis data menggunakan analisis univariate dan bivariate dengan uji chi square. Hasil yang didapat dari responden, kategori jenis kelamin laki-laki lebih banyak dari pada perempuan yaitu $67(72,8 \%)$ responden, rata-rata usia responden 34,15 tahun, dengan pekerjaan buruh sebanbanyak $33(35,9 \%)$ responden, pendidikan responden sebagian besar berpendidikan dasar SD-SMP/ Sederajat $49(53,2 \%)$ responden. Responden yang memiliki motivasi baik sebanyak $56(60,2 \%)$ responden, dan untuk responden yang mempunyai kepatuhan minum obat sebanyak $69(75,0 \%)$ responden. Uji statistik menggunakan uji chi square diperoleh nilai ( $p$-value $=0,000<a=0,05)$. Kesimpulan penelitian ini bahwa diketahui ada hubungan motivasi kesembuhan dengan kepatuhan minum obat pada penderita tuberkulosis paru di wilayah kerja Puskesmas Jambe Kabupaten Tangerang. Disarankan dapat meningkatkan motivasi kesembuhan pada penderita tuberkulosis paru dalam proses pengobatan dengan melakukan penyuluhan secara intensif pada penderita tuberkulosis paru, dan keluarga sebagai Pengawas Minum Obat (PMO).
\end{abstract}

Kata Kunci : Tuberkulosis, Motivasi, Kepatuhan

\section{ABSTRACT}

Tuberculosis remains a major killer by 2016. There are about 8.6 million people sufrendwith pulmonary TB and 1.3 million died from pulmonary tuberculosis. More than 95\% of deaths from Pulmonary TB in low and middle income countries (WHO, 2013).The purpose of this study to determine the relationship of healing motivation with drug adherence in patients with pulmonary TB in Puskesmas Jambe Kabupaten Tangerang.the work area this study a was descriptive analytic with cross sectional design approach. Sampling method used is Nonprobability Sampling with accidental sampling technique. Independent variable of research is healing motivation and dependent variable is medication adherence in Tuberculosis patients. The population of adult TB patients treated at PuskesmasJambeKabupatenTangerang 119 people with a sample size using Slovin formula obtained 92 respondents. The primary data were collected using questionnaires in the form of questionnaires, and secondary data collection from patient medical record files. Data analysis used univariate and bivariate analysis with chi square test. Result of respondents, male gender category more than 67 respondents (72,8\%), average age 34.15 years old, with $33(35,9 \%)$ respondents worker, education of respondents mostly primary education elementary-junior/ equivalent 49 (53,2\%) of respondents. Respondents who had good motivation were 56 (60.2\%) of respondents, and for respondents who had medication compliance were $69(75,0 \%)$ respondents. The statistical test using chi square test obtained value ( $p$-value = 0,000, $a=0,05)$. The conclusion of this research that there is known relation of healing motivation with medication adherence to tuberculosis patient in working area of PuskesmasJambeKabupatenTangerang. It is suggested to improve the motivation of healing in tuberculosis patients in the treatment process by doing intensive counseling on tuberculosis patients, and family as Drug Supervisor (PMO).

Keywords : Tuberculosis, Motivation, Compliance 


\section{LATAR BELAKANG}

TB Paru merupakan penyebab utama kematian terkait dengan resistensi antimikroba. Ada sekitar 8,6 juta orang jatuh sakit dengan TB Paru dan 1,3 juta meninggal akibat TB Paru. Lebih dari 95\% kematian akibat TB Paru di Negara berpenghasilan rendah dan menengah, WHO (2013).

World Health Organization (2012) Indonesia menempati urutan ke lima yaitu dengan prevalensi sebesar 289 per 100.000 penduduk. Berdasarkan laporan WHO dalam Global Tuberculosis Report, 2014 Indonesia menempati urutan kelima terbesar di dunia sebagai penyumbang penderita TB Paru.

Laporan Riset Kesehatan Daerah (Riskesda, 2010), memberikan gambaran bahwa di Provinsi Banten terdapat 1.282 per 100.000 penduduk. Berdasarkan komposisi penduduk, diketahui prevalensi Tuberkulosis paru paling banyak terdapat pada jenis kelamin laki-laki 819 per 100.000 penduduk, penduduk yang bertempat tinggal di desa 750 per 100.000 penduduk, kelompok pendidikan yang tidak sekolah 1.041 per 100.000 penduduk, petani/ nelayan/ buruh 858 per 100.000 penduduk.
Provinsi Banten terdapat 8.457 kasus TB Paru BTA positif menurut (Profil kesehatan provinsi Banten, 2015). Dari grafik Dinas Kesehatan Kabupaten penderita TB Paru BTA positif sebanyak 3.360 kasus dan berhasil ditemukan sebanyak 2.348 kasus, menurut (profil kesehatan Kab. Tangerang, 2014).

Studi pendahuluan yang dilakukan di Kelurahan Daru Wilayah Kerja Puskesmas Jambe Kabupaten Tangerang pada 10 orang warga desa usia produktif didapatkan 5 orang warga desa tidak patuh dalam minum obat yang diberikan puskesmas.

Dari uraian diatas peneliti tertarik untuk mengetahui "Hubungan Motivasi Kesembuhan Dengan Kepatuhan Minum Obat Pada Penderita Tuberkulosis Di Wilayah Kerja Puskesmas Jambe Kabupaten Tangerang”.

\section{METODE}

\section{Desain Penelitian}

Desain penelitian ini adalah penelitian deskkriptif analitik dengan pendekatan Cross Sectional. Penelitian Cross Sectional adalah dimana variabel sebab atau resiko dan akibat atau kasus yang terjadi pada objek penelitian diukur atau dikumpulkan secara simultan (dalam waktu yang 
bersamaan). Penelitian Survey yaitu suatu penelitian yang dilakukan tanpa melakukan intervensi terhadap suatu objek penelitian, sehingga sering disebut sebagai penelitian Non eksperiment, untuk mengetahui hubungan motivasi dengan kepatuhan minum obat penderita Tuberkulosis Paru di wilayah kerja Puskesmas Jambe Kabupaten Tangerang.

\section{Lokasi dan Waktu Penelitian}

Lokasi penelitian di poli paru dewasa wilayah kerja puskesmas Jambe Kabupaten Tangerang. Penelitian ini dilakukan pada bulan Oktober 2017 - Januari 2018. Penelitian dilaksanakan selama 2 minggu setiap hari Selasa dan Rabu pada tanggal 28 dan 29 Desember 2017, dan 2 dan 3 Januari 2018.

\section{Populasi}

Populasi pada penelitian ini adalah seluruh pasien Tuberkulosis Paru dewasa di wilayah kerja Puskesmas Jambe Kabupaten Tangerang yang berjumlah 119 orang pada bulan Januari sampai November 2017.

\section{Sampel}

Teknik pengambilan sampel dalam penelitian ini adalah acidental sampling. Dan sampel yang didapatkan peneliti sebesar 92 orang.

\section{Analisa Data}

Analisis univariate pada penelitian ini untuk mengetahui distribusi frekuensi pada karakteristik responden (jenis kelamin, umur, pendidikan, pekerjaan, motivasi kesembuhan, kepatuhan minum obat). Terdiri dari dua variabel yaitu hubungan motivasi kesembuhan sebagai variabel independent dan kepatuhan minum obat pada penderita tuberkulosis paru sebagai variabel dependent.

Analisis bivariate dalam penelitian ini dilakukan untuk mengetahui hubungan motivasi kesembuhan dengan kepatuhan minum obat pada penderita tuberkulosis paru menggunakan uji statistik Chi square (X2) dengan batas kemaknaan $a=0,05 \%$ apabila nilai $\mathrm{P}<$ a maka hasil perhitungan bermakna artinya ada hubungan motivasi kesembuhan dengan kepatuhan minum obat pada penderita tuberkulosis paru di poli tuberkulosis paru dewasa Puskesmas Jambe Kabupaten Tangerang. 


\section{HASIL PENELITIAN}

\section{ANALISA UNIVARIAT}

Tabel 5.1. Karakteristik Responden Berdasarkan Jenis Kelamin (n=92)

\begin{tabular}{|c|c|c|c|}
\hline No. & Jenis Kelamin & $\mathbf{n}$ & \% \\
\hline 1. & Laki-laki & 67 & 72,8 \\
\hline 2. & Perempuan & 25 & 27,2 \\
\hline & Total & 92 & 100 \\
\hline
\end{tabular}

Berdasarkan tabel 5.1 Distribusi frekuensi berjenis kelamin laki-laki 67 (72,8\%) responden berdasarkan jenis kelamin orang dari pada perempuan $25(27,2 \%)$ diperoleh sebagian besar responden orang.

Tabel 5.2.Karakteristik Responden Berdasarkan Umur (n=92)

\begin{tabular}{|c|c|c|c|}
\hline No. & Umur & $\mathbf{n}$ & \% \\
\hline 1. & $17-25$ th & 37 & 40,2 \\
\hline 2. & $26-35$ th & 19 & 20,7 \\
\hline 3. & $36-45$ th & 14 & 15,2 \\
\hline 4. & $>45$ th & 22 & 23,9 \\
\hline & Total & 92 & 100 \\
\hline
\end{tabular}

Berdasarkan Tabel 5.2 dapat dilihat bahwa statistik didapatkan rata-rata usia penderita umur responden dikelompokkan menjadi tuberkulosis paru adalah 34,15 tahun, empat kategori, berusia 15-25 tahun pembagian usia menurut Depkes RI (2009) sebanyak $37(40,2 \%)$ orang, responden dewasa remaja akhir yaitu 17-25 tahun, yang berusia 26-35 tahun sebanyak 19 dewasa awal yaitu 26-35 tahun, dewasa $(20,7 \%)$ orang, responden yang berusia 36- akhir yaitu 36-45 tahun, dan lansia awal 45 tahun sebanyak $14(15,2 \%)$ orang, >45 tahun.

responden yang berusia $>45$ tahun sebanyak 22 orang $(23,9 \%)$. Hasil analisis 
Tabel 5.3. Karakteristik Responden Berdasarkan Pendidikan (n=92)

\begin{tabular}{|c|c|c|c|}
\hline No. & Kategori & Jumlah & \% \\
\hline 1. & SD/ Sederajat & 21 & 22,8 \\
\hline 2. & SMP/ Sederajat & 28 & 30,4 \\
\hline 3. & SMA/ Sederajat & 34 & 37,0 \\
\hline 4. & Perguruan Tinggi & 9 & 9,8 \\
\hline & Total & 92 & 100 \\
\hline
\end{tabular}

Berdasarkan Tabel 5.3 dapat dilihat bahwa pendidikan responden dikelompokkan menjadi empat kategori berdasarkan hasil jawaban responden, yaitu responden yang berpendidikan SD/Sederajat ebanyak 21 $(22,8 \%)$ orang, responden yang berpendidikan SMP/Sederajat $28(30,4 \%)$ orang, berarti menunjukkan masih banyak responden yang berpendidikan dasar menurut Sisdiknas (2003) responden sebanyak $49(53,2 \%)$ yang berpendidikan dasar sehingga mempengaruhi pengetahuan responden. Responden yang berpendidikan SMA/Sederajat sebanyak 34 $(37,0 \%)$ orang, responden yang berpendidikan perguruan tinggi sebanyak 9 (9,8\%) orang.

Tabel 5.4. Karakteristik Responden Berdasarkan Pekerjaan (n=92)

\begin{tabular}{|c|c|c|c|}
\hline No. & Kategori & Jumlah (n) & Persentase (\%) \\
\hline 1. & Ibu Rumah Tangga & 16 & 17,4 \\
\hline 2. & Buruh & 33 & 35,9 \\
\hline 3. & Karyawan & 18 & 19,6 \\
\hline 4. & Pelajar & 10 & 10,9 \\
\hline 5. & Wiraswasta & 11 & 12,0 \\
\hline 6. & Guru & 4 & 4,3 \\
\hline \multicolumn{3}{|c|}{ yang sebagai pelajar sebanyak 10 (10,9\%), }
\end{tabular}

Berdasarkan Tabel 5.4 dapat dilihat bahwa pekerjaan responden dikelompokkan menjadi enam kategori berdasarkan hasil jawaban reponden, yaitu responden yang tidak bekerja atau ibu rumah tangga sebanyak $16(17,4 \%)$ orang, responden dapat dilihat $26(28,3 \%)$ orang yang tidak

bekerja. responden yang berkerja sebagai buruh $33(35,9 \%)$ orang sebagian besar responden sebagai buruh. Responden yang bekerja sebagai karyawan sebanyak 18 $(19,6 \%)$ orang, responden yang bekerja 
sebagai wiraswasta $11(12,0 \%)$ orang, dan terdapat $4(4,3 \%)$ orang. responden yang bekerja sebagai guru

Tabel 5.5. Karakteristik Responden Berdasarkan Motivasi Kesembuhan $(\mathbf{n}=92)$

\begin{tabular}{|c|c|c|c|}
\hline No. & Kategori & Jumlah (n) & Presentase (\%) \\
\hline 1. & Baik & 56 & 60,9 \\
\hline 2. & Kurang Baik & 36 & 39,1 \\
\hline & Total & 92 & 100 \\
\hline
\end{tabular}

Berdasarkan tabel 5.5 distribusi frekuensi motivasi kesembuhan dari 92 responden hasil jawaban responden. Motivasi kurang didapatkan bahwa motivasi kesembuhan baik diakibatkan kurangnya dukungan dari dengan kategori baik berjumlah 56 PMO dan tekad pada penderita $(60,2 \%)$ orang dan kategori kurang baik tuberkulosis paru dalam hal meminum obat berjumlah $36(39,1 \%)$ orang, berdasarkan sesuai jadwal.

Tabel 5.6. Karakteristik Responden Berdasarkan Kepatuhan Minum Obat (n=92)

\begin{tabular}{|c|c|c|c|}
\hline No. & Kategori & Jumlah $(\mathbf{n})$ & Persentasae $(\%)$ \\
\hline 1. & Patuh & 69 & 75,0 \\
\hline 2. & Tidak Patuh & 23 & 25,0 \\
\hline & Total & 92 & 100 \\
\hline
\end{tabular}

Berdasarkan tabel 5.6 distribusi frekuensi kepatuhan dari 92 responden didapatkan bahwa kepatuhan minum obat pada kategori patuh berjumlah 69 (75,0\%) orang dan kategori tidak patuh berjumlah 23

(25,0\%) orang. Terdapat angka ketidakpatuhan diakibatkan motivasi kesembuhan yang kurang serta kurangnya pengetahuan mengenai tuberkulosis sehingga penderita diasingkan. 


\section{BIVARIAT}

Tabel 5.7. Hubungan Motivasi Kesembuhan Dengan Kepatuhan Minum Obat Pada Penderita Tuberkulosis Paru di Wilayah Kerja Puskesmas Jambe Kabupaten Tangerang $(\mathbf{n}=92)$.

\begin{tabular}{|c|c|c|c|c|c|c|c|c|}
\hline \multirow[t]{3}{*}{ Motivasi } & \multicolumn{6}{|c|}{$\begin{array}{c}\text { Kepatuhan Minum Obat Pada Penderita } \\
\text { Tuberkulosis }\end{array}$} & \multirow{3}{*}{$\begin{array}{c}\text { (OR) } \\
95 \% \mathrm{CI}\end{array}$} & \multirow{3}{*}{$\begin{array}{c}\text { P-Value } \\
X^{2}\end{array}$} \\
\hline & \multicolumn{2}{|c|}{ Patuh } & \multicolumn{2}{|c|}{ Tidak Patuh } & \multicolumn{2}{|c|}{ Total } & & \\
\hline & $\mathbf{n}$ & $\%$ & $\mathbf{n}$ & $\%$ & $\mathbf{n}$ & $\%$ & & \\
\hline Baik & 53 & 94,6 & 3 & 5,4 & 56 & 100,0 & \multirow{3}{*}{$\begin{array}{l}22,08 \\
(5,80- \\
84,00)\end{array}$} & \multirow{3}{*}{0,000} \\
\hline Kurang Baik & 16 & 44,4 & 20 & 55,6 & 36 & 100,0 & & \\
\hline Total & 69 & $\mathbf{7 5 , 0}$ & 23 & 25,0 & 92 & 100,0 & & \\
\hline
\end{tabular}

Berdasarkan tabel 5.7 Analisa hubungan dengan confidence interval (CI) yaitu (95\% motivasi kesembuhan dengan kepatuhan minum obat pada penderita tuberkulosis paru diperoleh seperempatnya $20(55,6 \%)$ CI : 5,80-84,00) yang artinya 95\% diyakini dengan motivasi kesembuhan kurang baik bahwa rata-rata hubungan motivasi menyatakan tidak patuh. Sebagian besar kesembuhan dengan kepatuhan minum responden $53(94,6 \%)$ dengan motivasi obat pada penderita tuberkulosis paru hasil kesembuhan baik menyatakan patuh, terendah adalah 5,80 dan yang tertinggi sebagian kecil responden $3(5,4 \%)$ dengan adalah 84,00. Hasil uji statistik analisis motivasi kesembuhan baik menyatakan motivasi kesembuhan dengan kepatuhan tidak patuh, hampir seperempat responden minum obat pada penderita tuberkulosis $16(44,4 \%)$ dengan motivasi kesembuhan paru diperoleh nilai $p$-value $=0,000<a=$ kurang baik menyatakan patuh. 0,05 maka dapat disimpulkan bahwa Ada

Dari hasil uji statistik tersebut Hubungan Kepatuhan Minum Obat Pada didapatkan nilai OR (Odds Ratio $)=22,08$ Penderita Tuberkulosis Paru Di Wilayah yang berarti bahwa penderita tuberkulosis Kerja Puskesmas Jambe Kabupaten paru yang memiliki peluang 22,08 kali Tangerang. 


\section{PEMBAHASAN}

\section{Motivasi Kesembuhan}

Distribusi frekuensi responden berdasarkan berdasarkan motivasi kesembuhan diperoleh sebagian besar responden 56 $(60,9 \%)$ memiliki motivasi kesembuhan yang baik.

Motivasi mempunyai pengaruh yang cukup besar dalam penyembuhan pasien. Hal itu sesuai dengan yang dikatakan Siswanto 1999 dalam Widyatun (2009), bahwa motivasi kesembuhan sebagai salah satu objek studi psikologi kesehatan akan menentukan semangat juang para pasien untuk sembuh atau setidaknya mampu bertahan dalam menghadapi penyakit yang dideritanya.

Sejalan dengan penelitian (Muna \& Soleha, 2014) Motivasi dan dukungan keluarga sangat menunjang keberhasilan pengobatan seseorang dengan selalu mengingatkan penderita agar minum obat, perhatian yang diberikan kepada anggota keluarga yang sedang sakit dan memberi motivasi agar tetap rajin berobat, karena itu perlu diberikan pendidikan kesehatan tentang pentingnya kepatuhan pengobatan, motivasi dan dukungan keluarga kepada penderita supaya penderita menyelesaikan terapinya sampai sembuh.

\section{Kepatuhan Minum Obat Pada Penderita Tuberkulosis Paru}

Distribusi frekuensi kepatuhan minum obat pada penderita tuberkulosis paru didapatkan sebagian besar responden 69 $(75,0 \%)$ menyatakan patuh minum obat.

Menurut (Smet, 1994 dalam Ulfa, 2013) Kepatuhan atau ketaatan (compliancel adherence) adalah tingkat pasien melaksanakan cara pengobatan dan perilaku yang disarankan oleh dokternya atau orang lain. Kepatuhan pasien sebagai sejauh mana perilaku pasien sesuai dengan ketentuan yang diberikan oleh professional kesehatan (Niven, 2002). Sedangkan (Gabit 1999 dalam Ulfah, 2013) mendefinisikan kepatuhan atau ketaatan terhadap pengobatan medis adalah suatu kepatuhan pasien terhadap pengobatan yang telah ditentukan.

Sejalan dengan penelitian (Yuanasari 2009 dalam Beelt dkk, 2014) Seseorang dikatakan patuh berobat bila mau datang ke petugas kesehatan yang telah ditentukan sesuai dengan jadwal yang telah ditetapkan serta mau melaksanakan apa yang dianjurkan oleh petugas.

Hubungan Motivasi Kesembuhan Dengan Kepatuhan Minum Obat Pada Penderita Tuberkulosis Paru 
Dari hasil uji statistik tersebut didapatkan nilai OR (Odds Ratio $)=22,08$ yang berarti bahwa penderita tuberkulosis paru yang memiliki motivasi kesembuhan yang buruk memiliki peluang 22,08 kaliuntuk mengalami kejadian kepatuhan minum obat dengan confidence interval (CI) yaitu (95\% CI : 5,80-84,00) yang artinya $95 \%$ diyakini bahwa rata-rata hubungan motivasi kesembuhan dengan kepatuhan minum obat pada penderita tuberkulosis paru diperoleh nilai $\mathrm{p}$-value $=0,000<0,05$ maka dapat disimpulkan bahwa Ada Hubungan Antara Motivasi Kesembuhan Dengan Kepatuhan Minum Obat Pada Penderita Tuberkulosis Paru Di Wilayah Kerja Puskesmas Jambe Kabupaten Tangerang.

\section{KESIMPULAN DAN SARAN}

\section{Kesimpulan}

1. Teridentifikasi lebih dari setengahnya responden $56 \quad(60,9 \%)$ memiliki motivasi kesembuhan baik.

2. Teridentifikasi lebih dari setengahnya responden $69 \quad(75,0 \%)$ memiliki kepatuhan minum obat baik.

3. Teridentifikasi hasil analisa hubungan motivasi kesembuhan dengan kepatuhan minum obat pada penderita tuberkulosis paru di dapatkan $\mathrm{p}$ value $=$ $0,000<\mathrm{a}(0,05)$ yang artinya Ada Hubungan yang signifikan antara motivasi kesembuhan dengan kepatuhan minum obat pada penderita tuberkulosis paru.

\section{Saran}

1. Bagi Puskesmas Jambe

Diharapkan dapat mempertahankan dan meningkatkan pelayanan kesehatan khususnya pada poli TB Paru dan melakukan pemantauan terus-menerus pada pasien TB Paru dalam mengawasi kepatuhan minum obat serta penyuluhan kesehatan tentang pentingnya kepatuhan dalam minum obat, baik pada pasien maupun pada keluarganya sebagai PMO.

2. Bagi Peneliti Selanjutnya Diharapkan hasil penelitian ini dapat digunakan sebagai referensi untuk melakukan penelitian selanjutnya yang berkaitan dengan motivasi kesembuhan dengan kepatuhan minum obat pada penderita tuberkulosis paru di wilayah kerja puskesmas Jambe Kabupaten Tangerang dengan 
menambahkan beberapa variabel lainnya yang terkait.

3. Bagi STIKes Widya Dharma Husada

Diharapkan hasil penelitian ini menambah refrensi diperpustakaan yang dapat digunakan oleh mahasiswa dalam menyelesaikan tugas-tugas akademik.

\section{DAFTAR PUSTAKA}

Ulfah Maria. 2013. Hubungan Dukungan Keluarga Dengan Kepatuhan Minum Obat Pada Pasien Tuberkulosis (TBC) Di Wilayah Kerja Puskesmas Pamulang Kota Tangerang Selatan Tahun 2011. Skripsi. Jakarta: Universitas Islam Negeri Syarif Hidayatullah

Widayatun, Tri Rusmi. 2009. Ilmu Perilaku. Jakarta: Sagung Seto

Niven, Neil. 2002. Psikologi Kesehatan Pengantar Untuk Perawat \& Profesi Kesehatan Lain. Jakarta: EGC

Beelt, Christine Melinda, Ismanto, A. Yudi, Kallo Vandri. 2014. Hubungan Kepatuhan Pengobatan Dengan Hilangnya Gejala Klinis Tuberkulosis PAru Di Poli Paru RSUP Prof.Dr.R.D.kandou Manado. Jurnal diunduh pada tanggal 10 November 2017

Muna Latiful, \& Soleha Umdatus. 2014. Motivasi dan Dukungan Sosial Keluarga Mempengaruhi Kepatuhan Berobat Pada Pasien TB Paru Di Poli Paru BP4 Pamekasan. Jurnal Ilmiah
Kesehatan, Vol 7, No. 2, Agustus 2014 diunduh pada tanggal 10 November 2017

Kemenkes. 2009. Buku Saku Kader Program Penanggulangan TB. Direktorat Jenderal Pengendalian Penyakit dan Penyehatan Lingkungan Departemen Kesehatan Republik Indonesia 2009. Diunduh dari http://www.tbindonesia.or.id/opendir/ Buku/buku-saku-tb-revfinal.pdf pada tanggal 18 September 2017

2011. Stop TB Pedoman Nasional Pengendalian Tuberkulosis Kementrian Kesehatan Republik Indonesia Direktorat Jenderal Pengendalian Penyakit Dan Penyehatan Lingkungan 2011. Diunduh dari www.dokternida.rekansejawat.com pada tanggal 09 Oktober 2017

2011. Stop TB Terobosan Menuju Akses Universal Strategi Nasional Pengendalian TB Di Indonesia 2010-2014 Kementrian Kesehatan Republik Indonesia Direktorat Jendral Pengendalian Penyakit Dan Penyehatan Lingkungan 2011. Diunduh dari www.searo.who.int pada tanggal 22 November 2017

2016. Tuberkulosis Temukan Obati Sampai Sembuh. InfoDATIN: Pusat Data Dan Informasi Kementerian Kesehatan RI. Diunduh dari www.kemenkes.go.id pada tanggal 18 September 2017

2017. Tuberkulosis Kementrian Kesehatan Republik Indonesia. www.kemenkes.go.id 
